\title{
Biofilm-Forming Capacity in Biogenic Amine-Producing Bacteria Isolated from Dairy Products
}

\author{
Maria Diaz, Victor Ladero *, Beatriz del Rio, Begoña Redruello, María Fernández, \\ M. Cruz Martin and Miguel A. Alvarez
}

Department of Technology and Biotechnology of Dairy Products, Instituto de Productos Lácteos de Asturias (IPLA-CSIC), Villaviciosa, Spain

Biofilms on the surface of food industry equipment are reservoirs of potentially food-contaminating bacteria-both spoilage and pathogenic. However, the capacity of biogenic amine (BA)-producers to form biofilms has remained largely unexamined. BAs are low molecular weight, biologically active compounds that in food can reach concentrations high enough to be a toxicological hazard. Fermented foods, especially some types of cheese, accumulate the highest BA concentrations of all. The present work examines the biofilm-forming capacity of 56 BA-producing strains belonging to three genera and 10 species (12 Enterococcus faecalis, 6 Enterococcus faecium, 6

OPEN ACCESS

Edited by:

Giovanna Suzzi,

University of Teramo, Italy

Reviewed by:

Giorgia Perpetuini,

University of Teramo, Italy

Fausto Gardini,

University of Bologna, Italy

*Correspondence:

Victor Ladero

ladero@ipla.csic.es

Specialty section:

This article was submitted to

Food Microbiology,

a section of the journal

Frontiers in Microbiology

Received: 24 February 2016

Accepted: 11 April 2016

Published: 12 May 2016

Citation:

Diaz M, Ladero V, del Rio B,

Redruello B, Fernández M, Martin MC

and Alvarez MA (2016)

Biofilm-Forming Capacity in Biogenic

Amine-Producing Bacteria Isolated

from Dairy Products.

Front. Microbiol. 7:591.

doi: 10.3389/fmicb.2016.00591
Enterococcus durans, 1 Enterococcus hirae, 12 Lactococcus lactis, 7 Lactobacillus vaginalis, 2 Lactobacillus curvatus, 2 Lactobacillus brevis, 1 Lactobacillus reuteri, and 7 Lactobacillus parabuchneri), all isolated from dairy products. Strains of all the tested species - except for $L$. vaginalis - were able to produce biofilms on polystyrene and adhered to stainless steel. However, the biomass produced in biofilms was strain-dependent. These results suggest that biofilms may provide a route via which fermented foods can become contaminated by BA-producing microorganisms.

Keywords: biofilm, biogenic amines, histamine, tyramine, putrescine, lactic acid bacteria, dairy industry

\section{INTRODUCTION}

Food safety is a major priority in today's food industry. Bacterial biofilms on industrial surfaces are a cause for concern since they may act as reservoirs of contaminating microorganisms (Winkelströter et al., 2014). Dairy products in particular are susceptible to such contamination (Srey et al., 2013), with equipment surfaces one of its major sources (Kumar and Anand, 1998). Stainless steel type 304 is the most common material in contact with food in the dairy industry (Zottola and Sasahara, 1994). While inert, easy to clean and highly resistant to corrosion, it can, however, develop small cracks and crevices where biofilm formation is facilitated (Winkelströter et al., 2014). In addition, some parts of food processing equipment may have inaccessible areas where bacteria can evade cleaning treatments. The main biofilm-related risk is the growth of pathogens and spoilage microorganisms.

The capacity of biogenic amine (BA)-producers to form biofilms has not been investigated. BAs are low-molecular weight organic compounds derived from their corresponding amino acids via enzymatic decarboxylation. Although, BAs play an important role in human physiology, the ingestion of food containing them in large quantities can have toxicological effects on the digestive, circulatory, and respiratory systems (ten Brink et al., 1990; Shalaby, 1996; Ladero et al., 2010a). The 
most important BAs (both qualitatively and quantitatively) in foods and beverages are histamine, tyramine, and putrescine. Together with fish and wine, dairy products-especially cheesecan develop BA concentrations that may exceed $1000 \mathrm{mg} \mathrm{kg}^{-1}$ (Linares et al., 2012).

BAs form in food via the activity of bacteria with aminoacyl decarboxylase activity (Halasz et al., 1994). Their appearance in dairy products has mainly been attributed to Gram positive bacteria of the lactic acid bacteria (LAB) group. These can be present in the microbiota of milk, as part of the starter culture, or be introduced by contamination during manufacturing (Linares et al., 2011), with equipment surfaces a potentially important source of contamination (Novella-Rodríguez et al., 2004). The post-ripening processing of cheese, particularly grating, extends the contact of food with equipment surfaces, increasing the number of histamine-producing bacteria present in the final product (Ladero et al., 2009) and therefore the histamine concentration that may be reached.

The dairy histamine-producing species Lactobacillus parabuchneri has been reported to produce biofilms (Diaz et al., 2016b), but this capacity has not been studied in other BA producers. The aim of the present work was to test the ability of BA-producing bacteria isolated from different cheeses to form biofilms on polystyrene and adhere to stainless steel surfaces.

\section{MATERIALS AND METHODS}

\section{Bacterial Strains and Culture Conditions}

In this work we have examined the biofilm-forming capacity of 56 BA-producing strains belonging to three genera and 10 species (12 Enterococcus faecalis, 6 Enterococcus faecium, 6 Enterococcus durans, 1 Enterococcus hirae, 12 Lactococcus lactis, 7 Lactobacillus vaginalis, 2 Lactobacillus curvatus, 2 Lactobacillus brevis, 1 Lactobacillus reuteri, and 7 Lactobacillus parabuchneri), all isolated from dairy products. The ability of all (except of the Lactobacillus parabuchneri strains) to produce BAs was known from previous work (Ladero et al., 2010b,c, 2011a,b, 2012a,b; Diaz et al., 2015; del Rio et al., 2015). Given the reported ability of L. parabuchneri to form biofilms (Diaz et al., 2016b), and the apparent importance of the species in the accumulation of histamine in cheese (Diaz et al., 2016a), seven new strains isolated from cheese (following the protocol of Diaz et al., 2015) were included among those examined. These were identified at the species level by $16 S$ rRNA sequencing (Diaz et al., 2015) and their ability to produce histamine checked by UHPLC (Redruello et al., 2013).

Lactobacilli were grown at $37^{\circ} \mathrm{C}$ in MRS (Oxoid, Basingstoke, $\mathrm{UK})$, while enterococci and lactococci were grown at $30^{\circ} \mathrm{C}$ in M17 (Oxoid) supplemented with 0.5\% (w/v) glucose (GM17). To test the individual capacity of the L. parabuchneri strains to produce histamine, the culture medium was supplemented with $5 \mathrm{mM}$ histidine.

\section{Analysis of Biofilm Formation on Polystyrene}

The ability of the test strains to produce a biofilm on polystyrene was performed as described by Diaz et al. (2016b). Briefly, MRS or GM17 overnight cultures were diluted to approximately $10^{6}$ cfu $\mathrm{mL}^{-1}$ with fresh medium and used to fill polystyrene 96-well microtitre plates (Nunc ${ }^{\mathrm{TM}}$ MicroWell $^{\mathrm{TM}}$ Plates with a Nunclon ${ }^{\mathrm{TM}}$ Delta Surface; Thermo Fisher Scientific, Waltham, MA, USA). Negative controls consisted of wells filled with the corresponding uninoculated culture medium. All plates were then incubated at 30 or $37^{\circ} \mathrm{C}$ depending on the species. Biofilm biomass was determined using the crystal violet staining method ( $\mathrm{CV}$ assay) (Kubota et al., 2008). After 24, 30, or $48 \mathrm{~h}$ of incubation, the supernatant was removed and the wells rinsed with PBS buffer to eliminate non-adhered cells. The potential biofilm present was then stained with $0.5 \%(\mathrm{w} / \mathrm{v}) \mathrm{CV}$ in distilled water $\left(\mathrm{dH}_{2} \mathrm{O}\right)$; the excess dye was removed with $\mathrm{dH}_{2} \mathrm{O}$. The bound dye was then extracted using acetone/ethanol (80:20, v:v) and quantified by absorbance at $595 \mathrm{~nm}$ using a Benchmark Plus microplate spectrophotometer (BioRad, Hercules, CA, USA). The mean \pm SD of the optical density (OD) of three replicates was calculated for each strain. ANOVA with post-hoc Bonferroni correction was used to analyse all data. Significance was set at $p<0.05$. All statistical calculations were undertaken using SPSS v.15.0 software (SPSS Inc., IL, USA). Biofilm production capacity was expressed using cut-off values (Extremina et al., 2011). The cutoff value between biofilm-producers and non-producers (ODc) was defined as the mean of the negative controls (ODnc) plus three SDs. The strains were then classified as belonging to one of the following categories: ODc $<\mathrm{OD} \leq 2 \times \mathrm{ODc}=$ weak biofilm producer, $2 \times$ ODc $<$ OD $\leq 4 \times$ ODc $=$ moderate biofilm producer, and $\mathrm{OD}>4 \times \mathrm{ODc}=$ strong biofilm producer.

\section{Analysis of Bacterial Adherence to Stainless Steel}

The test surfaces used were $1 \mathrm{~cm}^{2}$ stainless steel (type AISI 304) coupons. These were washed with soap and $\mathrm{dH}_{2} \mathrm{O}$, rinsed with $\mathrm{dH}_{2} \mathrm{O}$, and then immersed in acetone for $30 \mathrm{~min}$ to remove any grease or fingerprints. They were then rinsed once again in $\mathrm{dH}_{2} \mathrm{O}$, autoclaved, and immersed singly in tubes containing MRS or GM17 broth inoculated with $10^{6} \mathrm{cfu} \mathrm{mL}^{-1}$ of the assayed strain (performed in triplicate). Each coupon was then incubated at 30 or $37^{\circ} \mathrm{C}$ for 24 or $48 \mathrm{~h}$ before removal using sterile forceps. Non-adhered cells were removed by rinsing the coupon three times in PBS buffer. The coupons were then reimmersed in $5 \mathrm{~mL}$ PBS buffer, and the adhered cells detached from the coupon by sonication in an ultrasonic bath (Ultrasons$\mathrm{H}$, Selecta, Spain) for $15 \mathrm{~min}$. The bacterial suspension produced was serially diluted in PBS, and $100 \mu \mathrm{L}$ of $10^{0}, 10^{-1}, 10^{-2}$, $10^{-3}$, and $10^{-4}$ dilutions were plated on MRS or GM17 and incubated for $48 \mathrm{~h}$ (Kruszewski et al., 2013). Three replicates were performed for each strain using independent bacterial cultures. Bacterial counts were expressed as $\log _{10} \mathrm{cfu} \mathrm{cm}^{-2}$ (mean \pm $\mathrm{SD}$ of three replicates). To confirm the tolerance of the cells to sonication, bacterial suspensions of all the examined strains were sonicated for $15 \mathrm{~min}$. Pre- and post-sonication suspensions were serially diluted in PBS, plated, incubated for $48 \mathrm{~h}$, and the cells enumerated; no significant differences were seen between preand post-sonication cell counts confirming that no cells were killed by this procedure. 


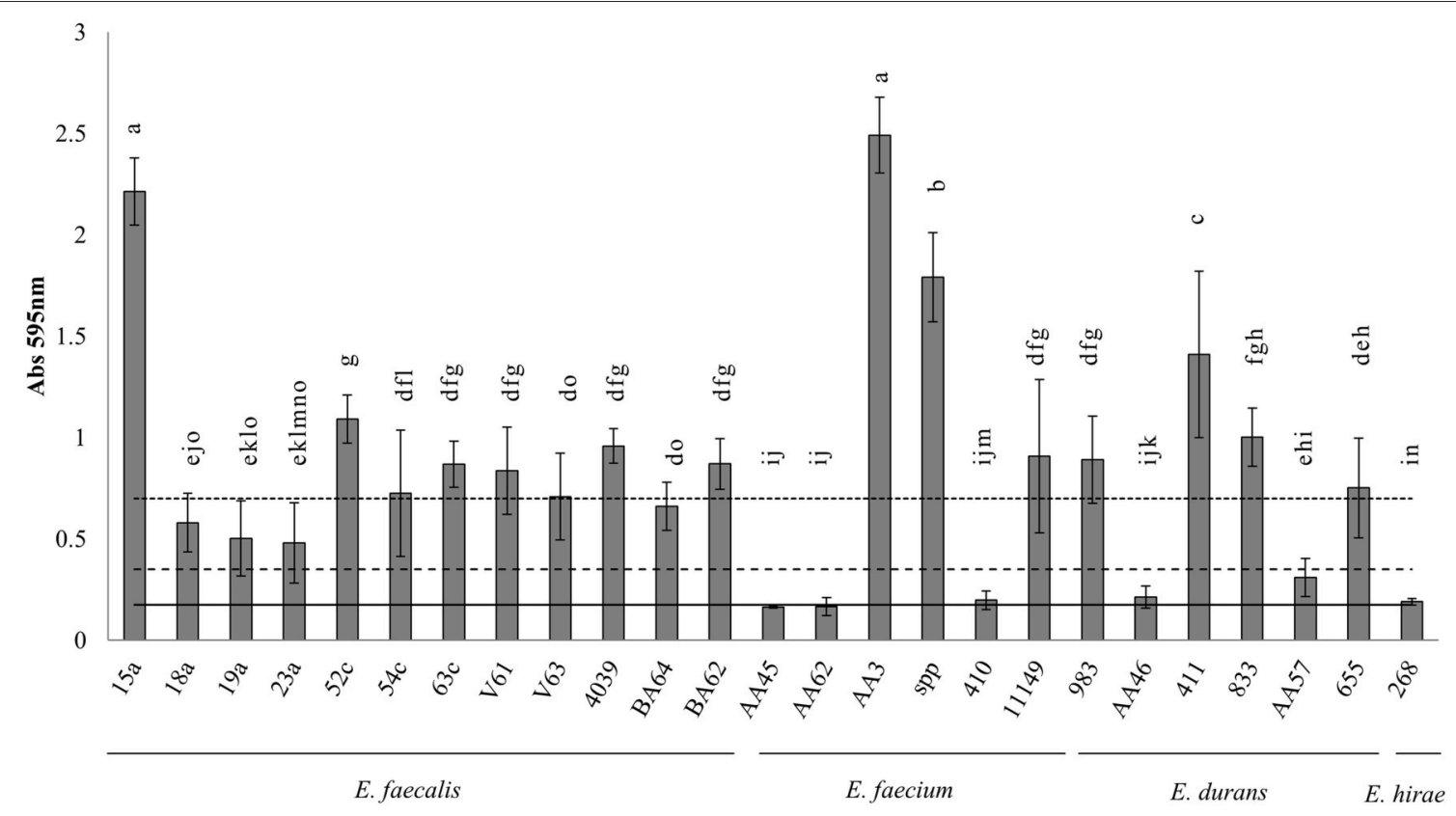

FIGURE 1 | Biofilm-producing capacity on polystyrene of the biogenic amine-producing Enterococcus strains after $30 \mathrm{~h}$ of incubation at $30^{\circ} \mathrm{C}$. Data represent means $\pm \mathrm{SD}$ (error bars) of three experiments. Values marked with the same letter do not differ significantly $(p>0.05$ according to the Bonferroni post-hoc test). (_ Cut-off line (ODc); (_ _ $2 \times$ ODc; (.......) $4 \times$ ODc.

\section{Scanning Electron Microscopy of Cells Adhered to Stainless Steel}

The method of Kubota et al. (2008) was followed, with some modifications, to observe by scanning electron microscopy (SEM) the cells adhered to the stainless steel coupons. Briefly, the latter were rinsed twice in PBS and then fixed in $2.5 \%$ glutaraldehyde (Sigma-Aldrich) in PBS for $16 \mathrm{~h}$ at room temperature. The fixed bacteria were then dehydrated using a graded series of acetone solutions (50-100\% v/v), and the coupons dried with $\mathrm{CO}_{2}$ using a CPD-030 critical point dryer (Bal-Tec AG, Balzers, Liechtenstein). They were then coated with gold using a SCD 004 Sputtering Coater (Bal-Tec AG, Balzers, Liechtenstein) and observed using a JSM-6610LV SEM (JEOL USA, Inc, Peabody, MA, USA).

\section{RESULTS}

\section{Biofilm Formation on Polystyrene}

Maximum biofilm biomass values were obtained at different times of incubation depending on the species. For all the Enterococcus strains assayed, biofilm biomass was maximal at $30 \mathrm{~h}$; for all the L. lactis, L. curvatus, and $L$. brevis strains, maximum values were reached at $24 \mathrm{~h}$; and for the $L$. reuteri and L. parabuchneri strains, maxima were recorded at $48 \mathrm{~h}$. All incubation time results shown are those at which maximum biomass was reached.

All the E. faecalis strains were able to form biofilms on polystyrene. Six were classified as strong biofilm producers, and six as moderate biofilm producers (Figure 1). The only E. hirae strain assayed was a weak biofilm producer (Figure 1). All the E. durans strains tested were able to form biofilms; four were strong biofilm producers, and two were weak producers (Figure 1). Of the six E. faecium strains analyzed, three were strong biofilm producers, one was a weak producer, and two were unable to form a biofilm (Figure 1).

All the L. lactis strains were able to produce biofilms on polystyrene (Figure 2). Three L. lactis subsp. cremoris and two $L$. lactis subsp. lactis were strong biofilm producers. The remaining strains-two L. lactis subsp. cremoris and five L. lactis subsp. lactis strains-were weak producers.

None of the $L$. vaginalis strains were able to form a biofilm (Figure 3). All the L. curvatus, L. brevis, and L. reuteri strains were, however, strong biofilm producers (Figure 3). Two out of seven L. parabuchneri strains were strong biofilm producers, while the remaining strains were only weak producers (Figure 3).

\section{Bacterial Adherence to Stainless Steel}

The strains selected for this assay were the strongest biofilm producers in the polystyrene surface assay, i.e., E. faecalis $15 \mathrm{a}, E$. hirae 268, E. durans 411, E. faecium AA3, L. lactis subsp. cremoris CECT 8666, L. lactis subsp. lactis 1AA59, L. curvatus VI6, L. brevis 3811 , L. parabuchneri IPLA 11150 , and L. reuteri IPLA 11078. Although, no L. vaginalis strain was able to form a biofilm on polystyrene, L. vaginalis IPLA 11064 was tested with the steel surface. Two incubation times ( 24 and $48 \mathrm{~h}$ ) were tested, but no differences were observed. Figure 4 shows the number of adhered 


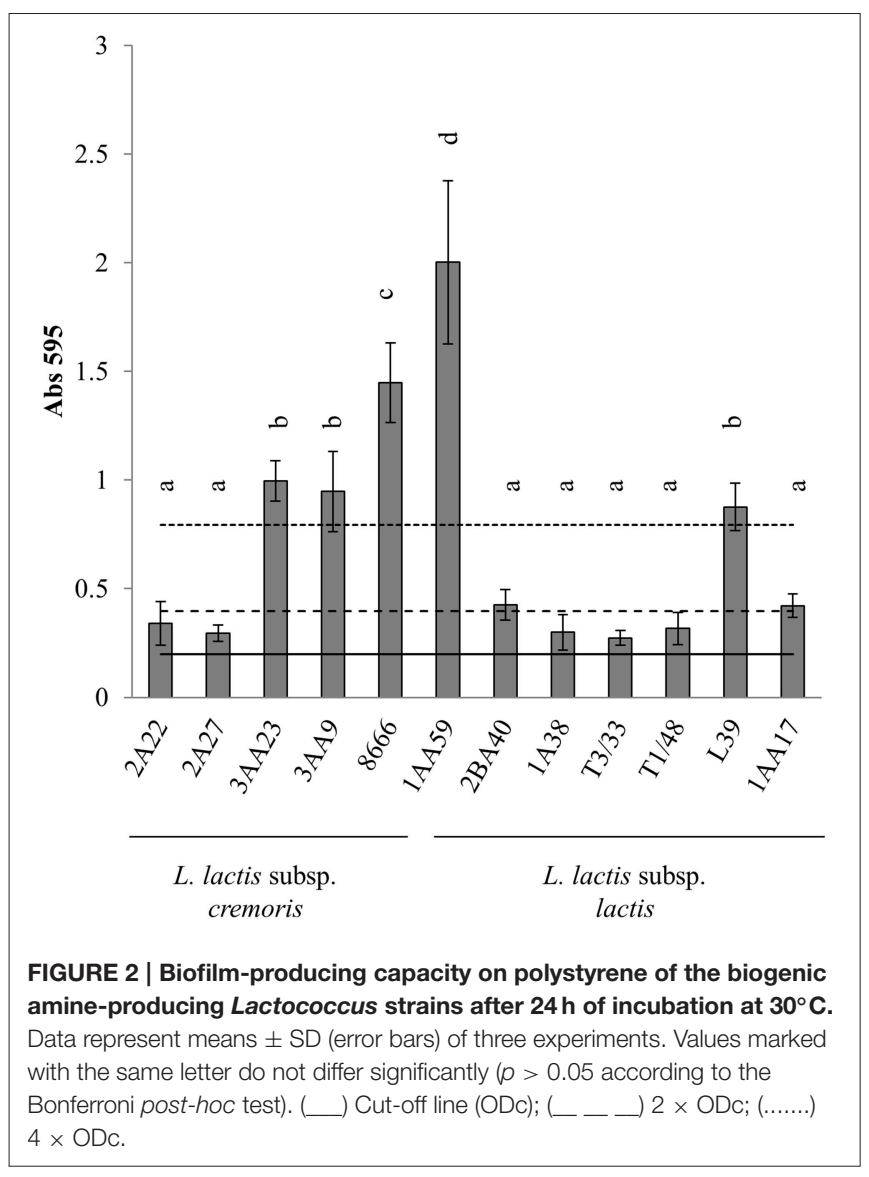

cells of each strain after incubation for $48 \mathrm{~h}\left(>10^{4} \mathrm{cfu} \mathrm{cm}^{-2}\right.$ for all strains assayed).

\section{Scanning Electron Microscopy Imaging of Cells}

SEM photomicrographs of cells adhered to the stainless steel coupons were captured for the same strains as used in the previous assay. Although, no differences were seen in the counts at different incubation times (24 and 48,h), differences in aggregation type and bacterial ultrastructure were observed.

E. faecalis 15a (Figure 5A1), E. faecium AA3 (Figure 5B1) and E. durans 411 returned clearer images after $24 \mathrm{~h}$ of incubation (data not shown) and appeared uniformly spread on the coupons. No adhering E. hirae 268 cells were observed at either 24 or $48 \mathrm{~h}$. The E. faecalis cells were observed embedded in an extracellular matrix (Figure 5A2); this was not observed for the other two species. Structures that might be involved in anchoring to the surface were observed on E. faecium cells (Figure 5B2).

L. lactis subsp. cremoris CECT 8666 and L. lactis subsp. lactis 1AA59 returned clearer images after $24 \mathrm{~h}$ of incubation. The strain 8666 was uniformly spread across the coupon surface (Figure 6A1), while 1AA59 formed more compact aggregates (Figure 6B1). In both cases, an extracellular matrix was observed, but with a different appearance (see Figures 6A2,A3,B2). Similar structures to those observed in E. faecium, and that might be involved in anchoring to the surface, were also observed for both L. lactis strains (Figures 6A3,B3).

L. parabuchneri IPLA 11150, L. reuteri IPLA 11078, and $L$. brevis 3811 returned clearer images after $48 \mathrm{~h}$ of incubation. $L$. vaginalis IPLA 11064 and L. curvatus VI6 showed no adhered cells at either 24 or $48 \mathrm{~h}$. L. parabuchneri was distributed across the coupon, showing aggregations with an extracellular matrix (Figures 7A1,A2). L. reuteri was distributed across the coupons in small aggregations (Figure 7B1) in a clear extracellular matrix (Figure 7B2). L. brevis was seen only in the fissures of the coupon (Figures 7C1,C2).

\section{DISCUSSION}

The formation of BA in fermented foods by bacteria, especially cheese, is a cause of much concern. The industrial equipment used in cheesemaking and processing is a source of contamination, and the ability of microorganisms to adhere to the surfaces of such equipment increases their contamination potential. In this work, the ability of $56 \mathrm{BA}$-producing dairy LAB strains to adhere to a polystyrene surface was examined using the $\mathrm{CV}$ assay, a technique that allows easy quantification of total biofilm biomass. The strongest biofilm producers of each species were then examined for their ability to adhere to stainless steel coupons, and the adhered cells observed by SEM.

The formation of biofilms by clinical Enterococcus isolates has been much studied since it affects pathogenic potential (Langsrud, 2009). However, enterococci are also a cause of concern for the food industry, and the biofilm-forming ability of several food-related Enterococcus species has also been studied (Gomes et al., 2008; Jahan and Holley, 2014; da Silva Fernandes et al., 2015). In the present study, the biofilm-forming capacity of tyramine- or tyramine and putrescine-producing Enterococcus species was examined. The results of the $\mathrm{CV}$ assay showed that all the strains analyzed, except for two E. faecium strains, were able to form biofilms, although the total biomass produced differed. These results agree with those of previous studies that showed several foodborne E. faecalis and E. faecium isolates to be either weak, moderate or strong biofilm producers, while some isolates formed no biofilm at all (Gomes et al., 2008; Jahan and Holley, 2014). E. durans has also been described as a strong or moderate biofilm producer (Amel et al., 2015; Pieniz et al., 2015). The only strain of $E$. hirae analyzed in the present work was a weak biofilm producer; to our knowledge, the capacity of this species to form biofilms has not been previously studied.

All the Enterococcus strains selected to see whether they could adhere to stainless steel did so, with counts reaching

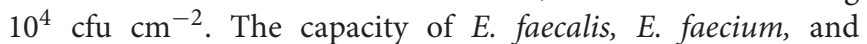
$E$. durans to adhere to stainless steel has been previously reported (Amel et al., 2015; da Silva Fernandes et al., 2015). The Enterococcus strains that adhered to the stainless steel coupons were observed by SEM, except for E. hirae 268; - this strain attached only weakly to the metal surface and was unable to resist the treatment required prior to observation. Of the strains that covered the surface of the steel coupons (Figure 5), none formed the complex three-dimensional structures reported 


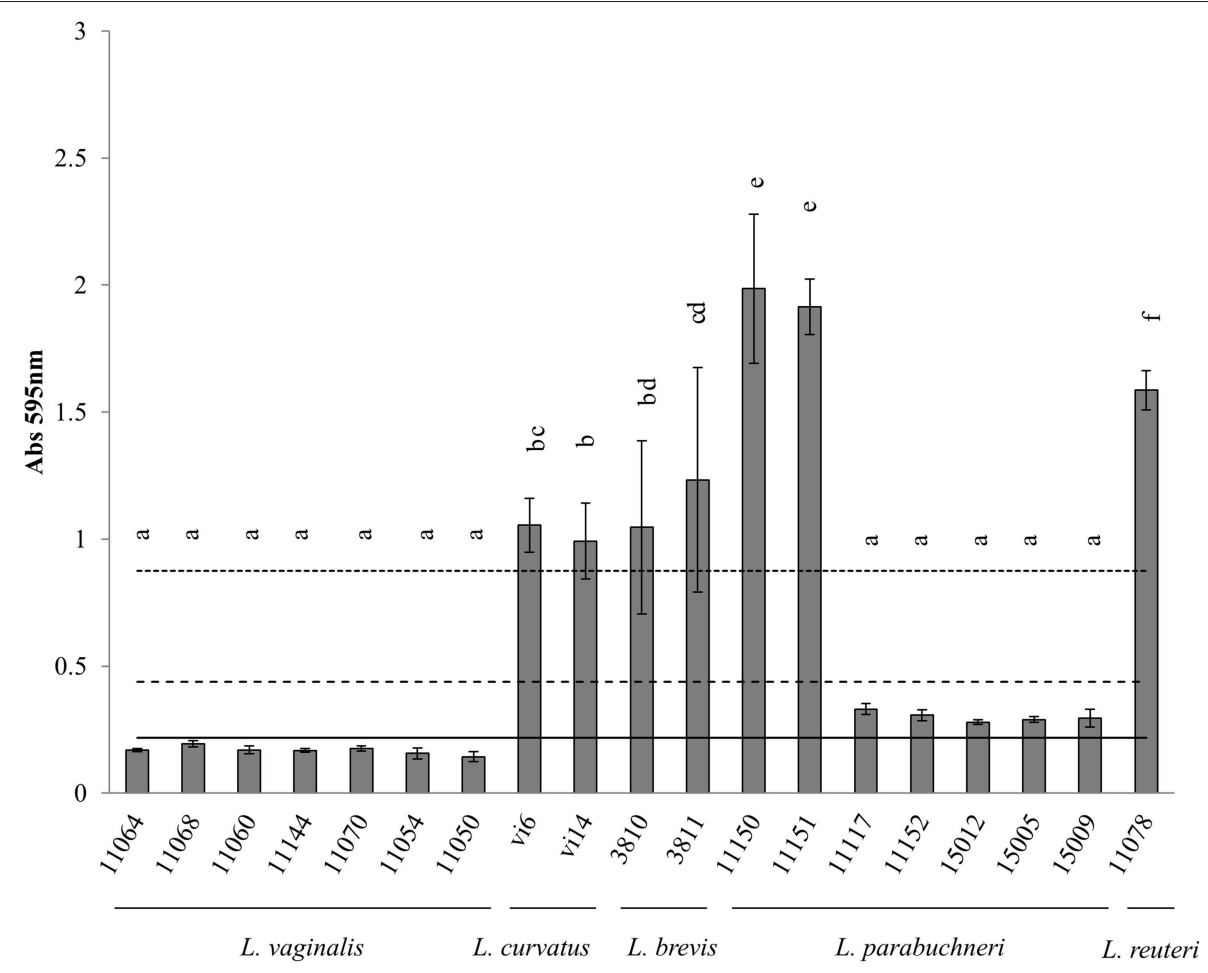

FIGURE 3 | Biofilm-producing capacity on polystyrene of the biogenic amine-producing Lactobacillus strains incubated at $37^{\circ} \mathrm{C}$. The $L$. vaginalis, $L$. curvatus and $L$. brevis strains were incubated for $24 \mathrm{~h}$. The $L$. parabuchneri and $L$. reuteri strains were incubated for $48 \mathrm{~h}$. Data represent means $\pm S D$ (error bars) of three experiments. Values marked with the same letter do not differ significantly $\left(p>0.05\right.$ according to the Bonferroni post-hoc test). ( $\_$) Cut-off line (ODc); ( $\_$_ $)$ $2 \times \mathrm{ODc} ;(\ldots . .)$.$4 \times ODc.$

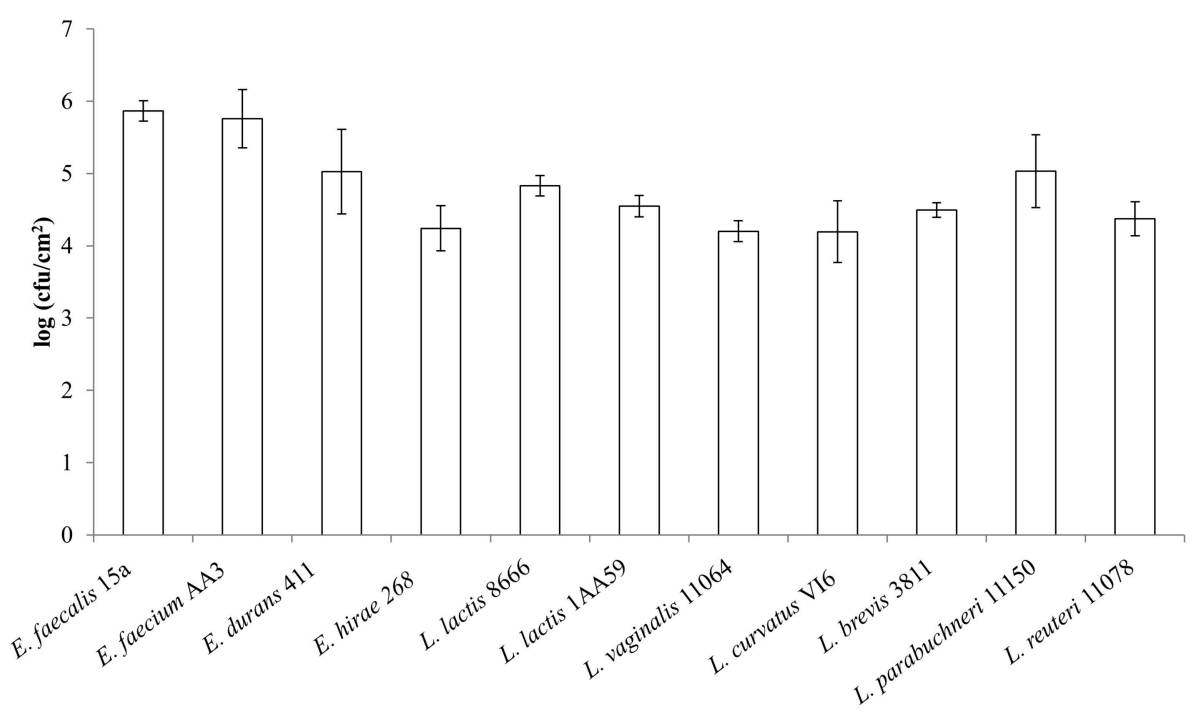

FIGURE 4 | Adherence to stainless steel coupons by biofilm-producing strains. Data are expressed as $\log _{10} \mathrm{cfu} / \mathrm{cm}^{2}$ and represent the mean $\pm \mathrm{SD}(\mathrm{error}$ bars) of three experiments.

by da Silva Fernandes et al. (2015). Some aggregations of E. faecalis 15a cells were observed (Figure 5A2), while E. faecium AA3 cells appeared separated from one another, but all cells were sufficiently well adhered not to be detached by the PBS washes or the treatment required prior to SEM observations. To our knowledge, this is the first time that images of E. durans cells adhered to stainless steel have been captured. 

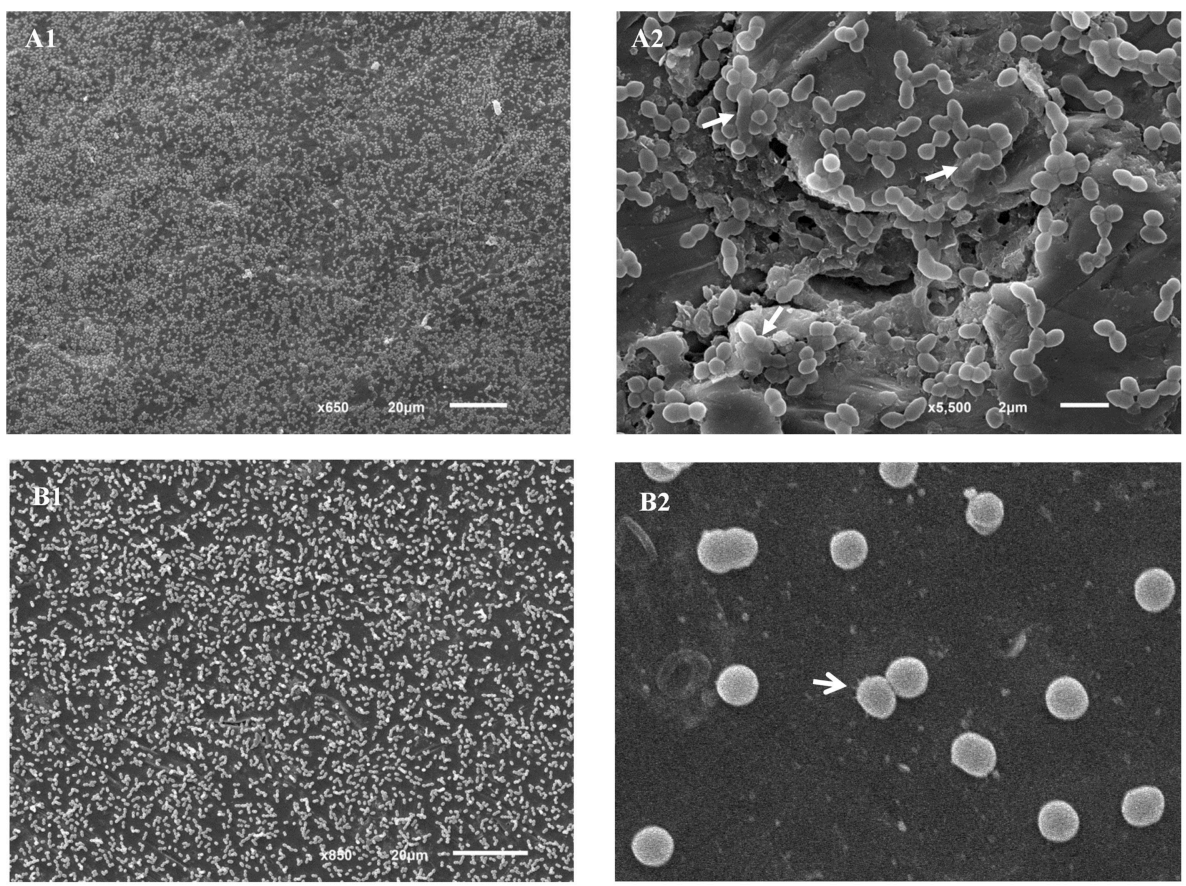

FIGURE 5 | Scanning electron photomicrographs of Enterococcus strains adhered to stainless steel coupons after $24 \mathrm{~h}$ of incubation. (A) E. faecalis 15a, (B) E. faecium AA3. Closed arrows point to the extracellular matrix; open arrows point to anchoring structures.

The ability of L. lactis to form a biofilm on a surface has been related to the latter's physicochemical properties (Giaouris et al., 2009; Oxaran et al., 2012). However, few studies have ever been performed on L. lactis biofilm formation. In the present work, 12 putrescine-producing L. lactis strains were shown by the $\mathrm{CV}$ assay to be either weak or strong biofilm producers. The two strains that most strongly formed biofim on polystyrene-L. lactis subsp. cremoris CECT 8666 and L. lactis subsp. lactis 1AA59-also adhered to stainless steel, reaching counts of $10^{4} \mathrm{cfu} \mathrm{cm}^{-2}$. SEM images showed cells of both strains to be embedded in an extracellular matrix and to be clearly adhered to the coupons. This is the first time that $L$. lactis adhered on stainless steel have been observed by SEM. Unlike that seen for enterococci, the L. lactis CECT 8666 cells showed tridimensional structures including filamentous ones that might help them adhere to the surface (Figures 6A2,A3). The extracellular material formed a pod-like covering over the cells (Figures 6A2,A3). L. lactis 1AA59 cell clusters also appeared to be attached via the extracellular matrix (Figure 6B2). For both L. lactis strains (Figures 6A3,B3) examined, and E. faecium AA3 (Figure 5B2), small protuberances of the cell surface were observed, which may have helped anchor the cells to the coupons. Certainly, aggregation and biofilm formation in L. lactis has been associated with the production of functional pili (Oxaran et al., 2012). Although, the adhesion of the putrescine-producing strains analyzed in this work would be undesirable for the food industry, allowing the development of L. lactis biofilms has been proposed as a means of preventing the growth of pathogens on food industry surfaces (Leriche et al., 1999; Zhao et al., 2004).
The presence of several Lactobacillus species (L. curvatus, Lactobacillus fermentum, Lactobacillus delbruekii, Lactobacillus paracasei, Lactobacillus plantarum, and L. reuteri) on the surfaces of dairy equipment has been reported (Somers et al., 2001; Scatassa et al., 2015). In the present work, two tyramine and putrescine-producing $L$. brevis strains were strong biofilm producers on polystyrene. This agrees with previous results for L. brevis strains isolated from onions (Kubota et al., 2008). The two tyramine-producing L. curvatus strains tested were also strong biofilm producers. Biofilm formation by L. curvatus has been previously described, although it was found to be a weaker biofilm producer than in the present work (Pérez Ibarreche et al., 2014). Fifteen histamine-producing strains, seven belonging to $L$. vaginalis, seven to $L$. parabuchneri and one to $L$. reuteri, were examined by the CV assay. The seven histamine-producing $L$. vaginalis strains were unable to form biofilms. All the $L$. parabuchneri strains were able to form biofilms, and were either weak or strong biofilm producers, depending on the strain. This agrees with the results of previous reports (Diaz et al., 2016b). The $L$. reuteri strain examined was a strong biofilm producer. Numerous studies have described the formation of biofilms by $L$. reuteri, some strains of which are considered probiotics (Leccese Terraf et al., 2014). A system regulating biofilm formation in L. reuteri was recently characterized (Su and Ganzle, 2014). In the present work, L. reuteri IPLA 11078, along with L. vaginalis IPLA 11064, L. curvatus VI6, L. brevis 3811 and L. parabuchneri IPLA 11150 were all able to adhere to the stainless steel coupons, and reached counts of over $10^{4} \mathrm{cfu} \mathrm{cm}^{-2}$. However, when the coupons were observed under the SEM, only L. parabuchneri 

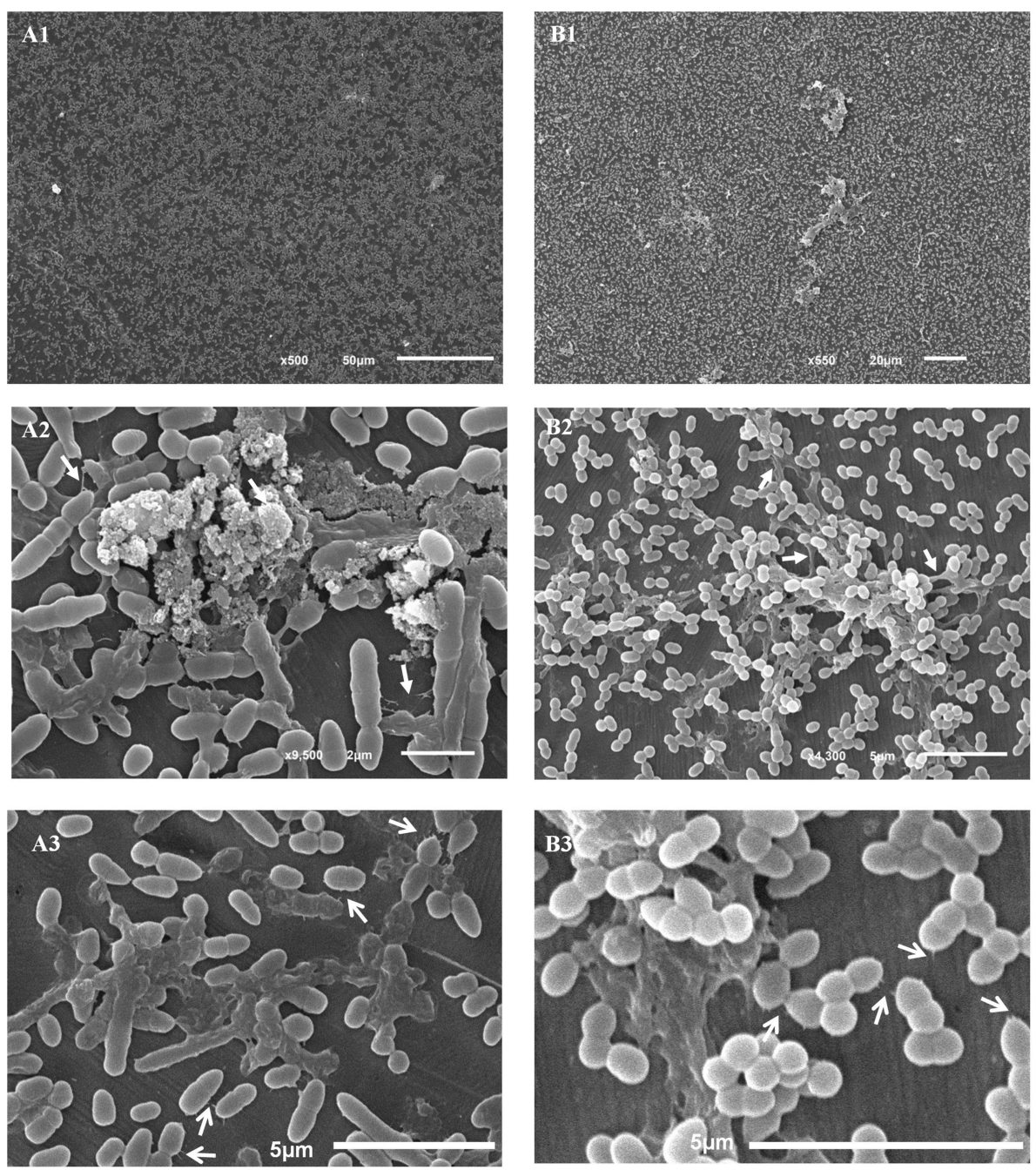

FIGURE 6 | Scanning electron photomicrographs of Lactococcus lactis strains adhered to stainless steel coupons after $24 \mathrm{~h}$ of incubation. (A) L. lactis subsp cremoris CECT8666, (B) L. lactis subsp. lactis 1AA59. Closed arrows point to the extracellular matrix; open arrows point to anchoring structures.

IPLA 11150 (Figure 7A) and L. reuteri IPLA 11078 (Figure 7B) cells were seen attached. For L. parabuchneri IPLA 11150, the cells aggregated into clumps composed of long chains of undivided cells. A previous study on Pseudomonas aeruginosa showed that elongated cells are inclined to form cohesive clumps (Yoon et al., 2011). According to the CV assay, the present $L$. parabuchneri and $L$. reuteri strains were strong biofilm producers. However, while the same assay suggested L. curvatus VI6 and L. brevis 3811 to be strong biofilm producers, the absorbance measured was very close to the lower limit for such classification. The few cells seen attached to the coupons might be the result of them not being able to resist the treatment required prior to SEM observation. This would appear to be supported by the fact that $L$. brevis 3811 was not homogenously attached to the surface of the coupons, but seen in their fissures. This is an important finding for the food industry since steel surfaces do develop cracks and these appear able to protect bacteria from cleaning procedures.
The present results show all the species examined, except L. vaginalis, had BA-producing strains able to form biofilms and that they could adhere to stainless steel, a material commonly used to make equipment in the food industry. Although, the cells attached to the stainless steel coupons commonly showed none of the three-dimensional structures reported by da Silva Fernandes et al. (2015), counts of over $10^{4} \mathrm{cfu} \mathrm{cm}^{-2}$ were recorded in all cases, with E. faecalis, E. faecium, E. durans, and $L$. parabuchneri exceeding $10^{5} \mathrm{cfu} \mathrm{cm}^{-2}$. Given the large surface area of industrial equipment, BA-producing bacteria that can adhere to steel clearly pose a food contamination threat. This problem is of particular concern in the dairy industry since post-ripening treatments such as cheese grating bring food into close and prolonged contact with equipment surfaces. In fact, it has already been shown that cheese that has undergone post-ripening processing (cutting, slicing, or grating) has higher histamine levels than non-processed cheese (Ladero et al., 2009). 

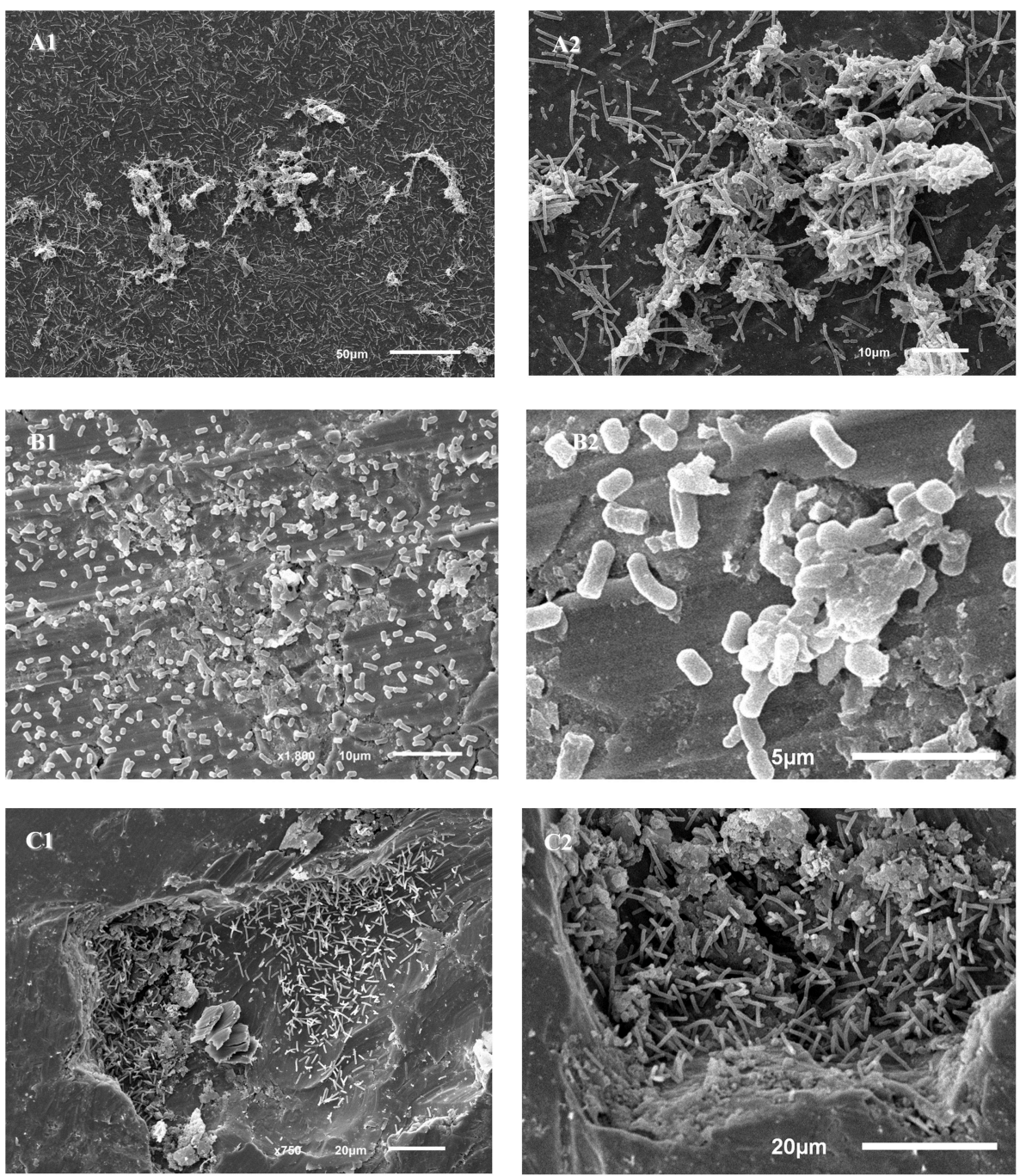

FIGURE 7 | Scanning electron photomicrographs of Lactobacillus strains adhered to stainless steel coupons after $48 \mathrm{~h}$ of incubation. (A) $L$. parabuchneri IPLA 11150, (B) L. reuteri IPLA 11078, (C) L. brevis 3811.

It is therefore important that our knowledge of the adhesion and biofilm forming capacities of BA-producers be improved, to prevent food contamination by these spoilage bacteria and eventually the accumulation of biogenic amines in food.

\section{AUTHOR CONTRIBUTIONS}

MD carried out the experiments and drafted the manuscript; $\mathrm{BR}, \mathrm{VL}$ collaborated in conducting some experiments; VL, Bd, and MF participated in the study design and writing of the manuscript; MC, MA provided the general concept, designed the experiments, and supervised the experimental work and the manuscript. All authors contributed to the discussion of the research and approved the final manuscript.

\section{ACKNOWLEDGMENTS}

The authors are very grateful to Prof. Christian Magni for providing some of the strains used in this work, the Unidad de Microscopía Electrónica y Microanálisis of the University of Oviedo for assistance with the SEM techniques, and Adrian Burton for language assistance. This work was funded by the Spanish Ministry of the Economy and Competitiveness (AGL2013-45431-R) and the Plan for Science, Technology and Innovation 2013-2017 financed by the European Regional Development Fund and the Principality of Asturias (GRUPIN14-137). MD is a beneficiary of an FPI fellowship from the Spanish Ministry of the Economy and Competitiveness. 


\section{REFERENCES}

Amel, A. M., Farida, B., and Djamila, S. (2015). Anti-adherence potential of Enterococcus durans cells and its cell-free supernatant on plastic and stainless steel against foodborne pathogens. Folia Microbiol. (Praha) 60, 357-363. doi: 10.1007/s12223-014-0367-6

da Silva Fernandes, M., Kabuki, D. Y., and Kuaye, A. Y. (2015). Biofilms of Enterococcus faecalis and Enterococcus faecium isolated from the processing of ricotta and the control of these pathogens through cleaning and sanitization procedures. Int. J. Food Microbiol. 200, 97-103. doi: 10.1016/j.ijfoodmicro.2015.02.004

del Rio, B., Ladero, V., Redruello, B., Linares, D. M., Fernández, M., Martin, M. C., et al. (2015). Lactose-mediated carbon catabolite repression of putrescine production in dairy Lactococcus lactis is strain dependent. Food Microbiol. 48, 163-170. doi: 10.1016/j.fm.2014.11.018

Diaz, M., del Rio, B., Ladero, V., Redruello, B., Fernández, M., Martin, M. C., et al. (2015). Isolation and typification of histamine-producing Lactobacillus vaginalis strains from cheese. Int. J. Food Microbiol. 215, 117-123. doi: 10.1016/j.ijfoodmicro.2015.08.026

Diaz, M., del Rio, B., Ladero, V., Redruello, B., Sanchez-Llana, E., Fernandez, M., et al. (2016b). Histamine-producing Lactobacillus parabuchneri strains isolated from grated cheese can form biofilms on stainless steel. Food Microbiol.

Diaz, M., Ladero, V., Redruello, B., Sanchez-Llana, E., del Rio, B., Fernandez, M., et al. (2016a). A PCR-DGGE method for the identification of histamine-producing bacteria in cheese. Food Control 63, 216-223. doi: 10.1016/j.foodcont.2015.11.035

Extremina, C. I., Costa, L., Aguiar, A. I., Peixe, L., and Fonseca, A. P. (2011). Optimization of processing conditions for the quantification of enterococci biofilms using microtitre-plates. J. Microbiol. Methods 84, 167-173. doi: 10.1016/j.mimet.2010.11.007

Giaouris, E., Chapot-Chartier, M. P., and Briandet, R. (2009). Surface physicochemical analysis of natural Lactococcus lactis strains reveals the existence of hydrophobic and low charged strains with altered adhesive properties. Int. J. Food Microbiol. 131, 2-9. doi: 10.1016/j.ijfoodmicro.2008.09.006

Gomes, B. C., Esteves, C. T., Palazzo, I. C., Darini, A. L., Felis, G. E., Sechi, L. A., et al. (2008). Prevalence and characterization of Enterococcus spp. isolated from Brazilian foods. Food Microbiol. 25, 668-675. doi: 10.1016/j.fm.2008. 03.008

Halasz, A., Barath, A., Simon-Sarkadi, L., and Holzapfel, W. (1994). Biogenic amines and their production by microorganisms in food. Trends Food Sci. Technol. 5, 42-49. doi: 10.1016/0924-2244(94)90070-1

Jahan, M., and Holley, R. A. (2014). Incidence of virulence factors in enterococci from raw and fermented meat and biofilm forming capacity at 25 degrees C and 37 degrees C. Int. J. Food Microbiol. 170, 65-69. doi: 10.1016/j.ijfoodmicro.2013.11.002

Kruszewski, K. M., Nistico, L., Longwell, M. J., Hynes, M. J., Maurer, J. A., HallStoodley, L., et al. (2013). Reducing Staphylococcus aureus biofilm formation on stainless steel 316L using functionalized self-assembled monolayers. Mater. Sci. Eng. C Mater. Biol. Appl. 33, 2059-2069. doi: 10.1016/j.msec.2013. 01.023

Kubota, H., Senda, S., Nomura, N., Tokuda, H., and Uchiyama, H. (2008). Biofilm formation by lactic acid bacteria and resistance to environmental stress. J. Biosci. Bioeng. 106, 381-386. doi: 10.1263/jbb.106.381

Kumar, C. G., and Anand, S. K. (1998). Significance of microbial biofilms in food industry: a review. Int. J. Food Microbiol. 42, 9-27. doi: 10.1016/S01681605(98)00060-9

Ladero, V., Calles-Enriquez, M., Fernandez, M., and Alvarez, M. A. (2010a). Toxicological effects of dietary biogenic amines. Curr. Nutr. Food Sci. 6, 145-156. doi: 10.2174/157340110791233256

Ladero, V., Canedo, E., Perez, M., Martin, M. C., Fernandez, M., and Alvarez, M. A. (2012a). Multiplex qPCR for the detection and quantification of putrescineproducing lactic acid bacteria in dairy products. Food Control 27, 307-313. doi: 10.1016/j.foodcont.2012.03.024

Ladero, V., Coton, M., Fernández, M., Buron, N., Martin, M. C., Guichard, H., et al. (2011a). Biogenic amines content in Spanish and French natural ciders: application of qPCR for quantitative detection of biogenic amine-producers. Food Microbiol. 28, 554-561. doi: 10.1016/j.fm.2010.11.005
Ladero, V., Fernández, M., and Alvarez, M. A. (2009). Effect of post-ripening processing on the histamine and histamine-producing bacteria contents of different cheeses. Int. Dairy J. 19, 759-762. doi: 10.1016/j.idairyj.2009.05.010

Ladero, V., Fernández, M., Calles-Enriquez, M., Sanchez-Llana, E., Canedo, E., Martin, M. C., et al. (2012b). Is the production of the biogenic amines tyramine and putrescine a species-level trait in enterococci? Food Microbiol. 30, 132-138. doi: 10.1016/j.fm.2011.12.016

Ladero, V., Fernández, M., Cuesta, I., and Alvarez, M. A. (2010b). Quantitative detection and identification of tyramine-producing enterococci and lactobacilli in cheese by multiplex qPCR. Food Microbiol. 27, 933-939. doi: 10.1016/j.fm.2010.05.026

Ladero, V., Martinez, N., Martin, M. C., Fernandez, M., and Alvarez, M. A. (2010c). qPCR for quantitative detection of tyramine-producing bacteria in dairy products. Food Res. Int. 43, 289-295. doi: 10.1016/j.foodres.2009. 10.007

Ladero, V., Rattray, F. P., Mayo, B., Martín, M. C., Fernández, M., and Alvarez, M. A. (2011b). Sequencing and transcriptional analysis of the biosynthesis gene cluster of putrescine-producing Lactococcus lactis. Appl. Environ. Microbiol. 77, 6409-6418. doi: 10.1128/AEM.05507-11

Langsrud, S. (2009). "Biofilm formation by Gram-positive bacteria including Staphylococcus aureus, Mycobacterium avium and Enterococcus spp. in food processing environments," in Biofilms in the Food and Beverage Industries, eds P. Fratamico, B. Annous, and N. Gunther (Cambridge: Woodhead Publishing), 250-269.

Leccese Terraf, M. C., Mendoza, L. M., Juárez Tomás, M. S., Silva, C., and NaderMacías, M. E. F. (2014). Phenotypic surface properties (aggregation, adhesion and biofilm formation) and presence of related genes in beneficial vaginal lactobacilli. J. Appl. Microbiol. 117, 1761-1772. doi: 10.1111/jam.12642

Leriche, V., Chassaing, D., and Carpentier, B. (1999). Behaviour of $L$ monocytogenes in an artificially made biofilm of a nisin-producing strain of Lactococcus lactis. Int. J. Food Microbiol. 51, 169-182. doi: 10.1016/S01681605(99)00128-2

Linares, D. M., del Río, B., Ladero, V., Martínez, N., Fernández, M., Martín, M. C., et al. (2012). Factors influencing biogenic amines accumulation in dairy products. Front. Microbiol. 3:180. doi: 10.3389/fmicb.2012.00180

Linares, D. M., Martín, M. C., Ladero, V., Alvarez, M. A., and Fernández, M. (2011). Biogenic amines in dairy products. Crit. Rev. Food Sci. Nutr. 51, 691-703. doi: 10.1080/10408398.2011.582813

Novella-Rodríguez, S. N., Veciana-Nogues, M. T., Roig-Sagués, A. X., TrujilloMesa, A. J., and Vidal-Carou, M. C. (2004). Evaluation of biogenic amines and microbial counts throughout the ripening of goat cheeses from pasteurized and raw milk. J. Dairy Res. 71, 245-252. doi: 10.1017/S0022029904000147

Oxaran, V., Ledue-Clier, F., Dieye, Y., Herry, J. M., Péchoux, C., Meylheuc, T., et al. (2012). Pilus biogenesis in Lactococcus lactis: molecular characterization and role in aggregation and biofilm formation. PLoS ONE 7:e50989. doi: 10.1371/journal.pone.0050989

Pérez Ibarreche, M., Castellano, P., and Vignolo, G. (2014). Evaluation of antiListeria meat borne Lactobacillus for biofilm formation on selected abiotic surfaces. Meat Sci. 96, 295-303. doi: 10.1016/j.meatsci.2013.07.010

Pieniz, S., De Moura, T. M., Cassenego, A. P. V., Andreazza, R., Frazzon, A. P. G., Camargo, F. A. O., et al. (2015). Evaluation of resistance genes and virulence factors in a food isolated Enterococcus durans with potential probiotic effect. Food Control 51, 49-54. doi: 10.1016/j.foodcont.2014.11.012

Redruello, B., Ladero, V., Cuesta, I., Álvarez-Buylla, J. R., Martin, M. C., Fernandez, M., et al. (2013). A fast, reliable, ultra high performance liquid chromatography method for the simultaneous determination of amino acids, biogenic amines and ammonium ions in cheese, using diethyl ethoxymethylenemalonate as a derivatising agent. Food Chem. 139, 1029-1035. doi: 10.1016/j.foodchem.2013.01.071

Scatassa, M. L., Gaglio, R., Macaluso, G., Francesca, N., Randazzo, W., Cardamone, C., et al. (2015). Transfer, composition and technological characterization of the lactic acid bacterial populations of the wooden vats used to produce traditional stretched cheeses. Food Microbiol. 52, 31-41. doi: 10.1016/j.fm.2015. 06.008

Shalaby, A. R. (1996). Significance of biogenic amines to food safety and human health. Food Res. Int. 29, 675-690. doi: 10.1016/S0963-9969(96)00066-X

Somers, E. B., Johnson, M. E., and Wong, A. C. (2001). Biofilm formation and contamination of cheese by nonstarter lactic acid bacteria in the 
dairy environment. J. Dairy Sci. 84, 1926-1936. doi: 10.3168/jds.S00220302(01)74634-6

Srey, S., Jahid, I. K., and Ha, S. D. (2013). Biofilm formation in food industries: a food safety concern. Food Control 31, 572-585. doi: 10.1016/j.foodcont.2012.12.001

Su, M. S., and Gänzle, M. G. (2014). Novel two-component regulatory systems play a role in biofilm formation of Lactobacillus reuteri rodent isolate 100-23. Microbiology 160, 795-806. doi: 10.1099/mic.0.071399-0

ten Brink, B., Damink, C., Joosten, H. M., and Huis in 'T Veld, J. H. J. (1990). Occurrence and formation of biologically active amines in foods. Int. J. Food Microbiol. 11, 73-84. doi: 10.1016/0168-1605(90)90040-C

Winkelströter, L. K., Teixeira, F. B., Silva, E. P., Alves, V. F., and de Martinis, E. C. (2014). Unraveling microbial biofilms of importance for food microbiology. Microb. Ecol. 68, 35-46. doi: 10.1007/s00248-013-0347-4

Yoon, M. Y., Lee, K. M., Park, Y., and Yoon, S. S. (2011). Contribution of cell elongation to the biofilm formation of Pseudomonas aeruginosa during anaerobic respiration. PLOS ONE 6:e16105. doi: 10.1371/journal.pone.00 16105
Zhao, T., Doyle, M. P., and Zhao, P. (2004). Control of Listeria monocytogenes in a biofilm by competitive-exclusion microorganisms. Appl. Environ. Microbiol. 70, 3996-4003. doi: 10.1128/AEM.70.7.3996-4003.2004

Zottola, E. A., and Sasahara, K. C. (1994). Microbial biofilms in the food processing industry-should they be a concern? Int. J. Food Microbiol. 23, 125-148. doi: 10.1016/0168-1605(94)90047-7

Conflict of Interest Statement: The authors declare that the research was conducted in the absence of any commercial or financial relationships that could be construed as a potential conflict of interest.

Copyright (C) 2016 Diaz, Ladero, del Rio, Redruello, Fernández, Martin and Alvarez. This is an open-access article distributed under the terms of the Creative Commons Attribution License (CC BY). The use, distribution or reproduction in other forums is permitted, provided the original author(s) or licensor are credited and that the original publication in this journal is cited, in accordance with accepted academic practice. No use, distribution or reproduction is permitted which does not comply with these terms. 